\title{
For want of a four-cent pull chain
}

\section{Michel Villette}

Correspondence to Professor Michel Villette, Professor of Sociology, AgroParisTech and Researcher, Centre Maurice Halbwachs ENS/EHESS/ CNRS Paris, 63 quai de Seine 75019 Paris France; michel. villette@agroparistech.fr

Accepted 4 August 2011 Published Online First 15 September 2011
A noted French ethnographer describes his care in a French private hospital for a hip replacement. He recounts a number of events that are probably typical of many patients' hospital experiences, but which clinicians often do not perceive. The observations are probably similar to those patients might make after exposure to any modern healthcare system, except that they offer a level of detail few would provide. The account focuses on the contradiction between excellent technical operations and the absence of compassionate patient care, basic civility and the needs of patient safety. It addresses marketing of hospital services, staffing levels, conflicts between private enterprise and medical need, fragmented billing, disconnected after-care, and the absence of a coherent view of a patient's experience-the non-coordination of care. The author is not an expert in healthcare, and so refrains from offering specific recommendations, but hopes that his experience will stimulate professionals and researchers involved in improving healthcare to reflect on the many seemingly minor ways modern care causes distress or even harm. While minor from a technical point of view, these distressing incidents powerfully shape patients' experience of the care they receive.

I recount the events of my hospitalisation for a hip replacement. Each of the events may appear as a minor incident, a little nothing, in a large professional operation. From the point of view of the patient, however, each of these 'little nothings' cause unnecessary suffering, anxiety or discomfort at a minimum, but sometimes significant dangers for the patient, whether he or she is conscious of them or not. Moreover, these incidents, minor as each may appear to workers in the system, can cohere into a story that shapes a patient's overall image of the healthcare system. In my case, the story seemed to be one in which nobody on the hospital floor was there to listen to me and nobody seemed to care when they were there.
The staff seemed perpetually elsewhere, carrying out other prescribed duties.

In telling my story, I make no pretence of representing the views of the hospital administration. Nor do I point to any remedies. My purpose lies in inviting readers to reflect on the philosophy of care underlying the modern care organisation and stimulating thoughts about improvement.

\section{ADMISSION}

When it became clear I needed surgery to replace my hip, I chose this private hospital simply because of its location-next door to my home. I was also aware that the hospital specialised in orthopaedics and enjoyed a good reputation. Moreover, my mother and daughters had successfully undergone treatment there. While some public hospitals in Paris would doubtless have offered at least the same promise (and lower costs), I did not pursue other options.

I felt confident when the day of my hospitalisation arrived. I was sold on a 'deluxe room', which promised tranquillity. I did not expect to encounter any particular difficulties, especially since the anaesthesiologist assured me that 'it is nothing at all' and that I would 'walk the day after the operation'.

\section{Then came the day}

On arrival in the hospital's spacious lobby, I had to wait $15 \mathrm{~min}$ before the receptionist, busy making appointments on the telephone, finally invited me, with a brief nod, to sit down. Nobody seemed to be expecting me; no one offered a simple welcome to make me more comfortable. Maybe my greeting would be different on the third floor, where the orthopaedic surgery unit is located. Sadly, the first and third floors seemed to lack any connection save their common lack of civility. I was an anxious patient awaiting major surgery, but no one acknowledged me as anything other than a customer. I could have been in a department store buying shoes. 
I had become no more than a number, which I did in fact take so that I could wait to be called by a secretary for an admittance procedure, which focused only on billing. Once in front of the billing clerk, I discovered that the insurance I had purchased specifically to cover costs beyond those provided by the public system would not in fact cover all such costs.

The billing clerk asked who would pay for the excess fees charged by doctors ( $€ 700$, about $\$ 1100$ ) and by the anaesthesiologist $(€ 350)$, and for the single room supplement? Good question. To find the answer to this question, I made a phone call to the insurance company. The answer was neither clear nor reassuring: 'Yes, no, yes, maybe, it depends; we will have to calculate... But to calculate, we must have the invoice.' Since I was not about to go home only to go through all this again, I provided the payment myself and avoided dwelling further on issues of payment at the time of my admission.

A week after my surgery, someone from the insurance company accused the hospital of overcharging and reproached me for not having negotiated a better price on the day of my admission. Apparently, patients must balance anxiety about impending treatment with the demeanour of a cool, professional negotiator.

\section{PROMISES AND ASSURANCES}

Once on the third floor, I dutifully underwent the preoperative procedures: last x-rays, last blood and urine tests, last meals and a last visit from the anaesthetist to reassure me, with a broad smile: 'don't worry, everything will be OK.' Finally, a small pill to help me sleep.

Before falling asleep, I casually leafed through the glossy brochures provided by the hospital: 'The patient is at the heart of our system-one that strives to offer the ideal conditions of access to care, in terms of efficacy and safety, which therefore must provide the patient with a comfortable and enjoyable experience.'

'In this establishment, we commit ourselves to take care of your pain.' An impressive signature reinforced this reassuring statement: 'the French Republic, Ministry of Health and of the Family and Disability', accompanied by the logo of the French state, imprinted as if the State authority were an analgesic, a sort of republican talisman.

A reference to Article L.1110-5 of the Code of Public Health also appeared: 'Everyone has the right to receive treatment to relieve his pain. This must be prevented under all circumstances, evaluated, considered and treated...' By Jove, if pain is forbidden by the law, my tranquillity is guaranteed!

I also noticed a section entitled 'Composition of the Committee on Relations with the Users and the Quality of Care'. The existence of this committee suggested that ideal care can fall short of the ideal. Though, wanting to remain optimistic, I paid little attention to this at that time. Writing these lines now, I notice that the brochure does not indicate how patients should contact that committee. 'The rights of patients are respected', and each patient has the right to 'express his grievances', but apparently not the right to a phone number, address or even a name to address any grievances concerning these rights.

Not alarmed by the brochure's inconsistencies and superficial promises, I fell asleep.

\section{UNPROBLEMATIC PATIENTS}

The surgery took place the next day at 8:00. From a purely technical point of view, the surgery and anaesthesia went well. I arrived in the hospital practically crippled, and I left with a solid and well-positioned ceramic joint. The hospital skilfully executed its central task. However, a different picture emerges when one focuses on the details along the trajectory of my care.

Having made it through surgery without complication, I was considered an 'unproblematic' patient. In fact, such an 'unproblematic' patient is actually very weak. Even uncomplicated surgery is an assault on the body and can render a person defenceless, a vulnerable child utterly at the mercy of the normal functioning of the hospital. Indeed, the label 'unproblematic' can compound this situation as staff deem such patients as requiring little attention.

\section{Even the simplest things}

My difficulties started at 1:00 in the morning, when I realised that the light cord above my bed was broken, and the button I would normally use to tilt the electric bed was inaccessible in my current state. This may seem like a tiny detail, but imagine that you have to use the bedside urinal but can't seem to do it.

A kind nurse finally came in to fix the light. She extended the cord with a plastic tube, informing me this was hardly the first time that she made this repair. Each week, this short-term fix was undone by the hospital's cleaners, who understandably removed the tube. (The weekly repetition of this cycle vividly reminded me of the article 'Why hospitals don't learn from failures'. ${ }^{1}$ )

Unfortunately, no one had a similar solution for the broken ice machine. Ice helps alleviate postoperative pain, but the hospital's only ice machine was broken and would take 3 days to repair. Nurses had asked for a second ice machine, but apparently no money for this existed in the budget. The pain became unbearable, and the French state and its Ministry of Health's Family and Disability Division were not available when I needed it. 


\section{Pain at night}

I approached my third night in a pitiful state. The unidentified attendant left in charge of us was very unfriendly. Was he a nurse or a medical student stressed by the prospect of an upcoming exam? I didn't know. What I did know is that all he wanted to do was sleep. A desire I ardently shared.

At my first cries for help, he responded with double my usual pain killers and a strong dose of morphine. Two hours later, still unable to sleep because of the pain, I vomited, probably from too much pain medicine, which although ineffective at managing the pain, was very effective at inducing nausea. I called for a basin, but couldn't wait for it to arrive and therefore was completely covered in vomit. Not only was my leg was killing me, but now I was I filthy as well. On seeing the mess, the night attendant was clearly disgusted and disapproving. He stood at the entrance of the room without doing anything to help. Firmly, I asked him to get me a towel and gloves from the bathroom and he complied. He then quickly disappeared, but not before making it clear that I should not disturb him again.

\section{Feeding the patient}

Despite various difficulties and with the skilful support of a caring and sensitive nurse, the pain subsided. I was now able to eat.

Each morning for breakfast, a portion of butter, a serving of jam and two buns arrived on my meal tray. It was, however, impossible to fill the four slices of bread with the amount of butter and jam provided. Each morning I asked politely for more butter and jam. Each morning the server told me that, unfortunately, the trolley never contained any extra butter or jam. I discovered at the end of my stay that any extra butter or jam required at an extra charge - this on top of what I've already paid for the inoperative light switch and broken ice machine.

\section{The crazy bed}

Since the day I arrived, the electrical control of my hospital bed had exhibited some weird quirks. One night, I barely pressed the button, and yet the bed started closing inexorably in on me. I was locked in an uncontrolled spasm of closing, backing off slightly and then again closing. It was like a Charlie Chaplin movie but with pain and fear while I remained a prisoner of the machine. Luckily, this was on one of my last, not first, nights in the hospital and I was not totally helpless after coming out of surgery.

A lovely night nurse came in to free me by pulling the plug on the bed. We joked and she admitted that this machine was not up to date and often broken. The next day, I recounted my experience with the bed to the physician in a light-hearted fashion. He didn't laugh but explained very seriously a change in hospital ownership had left no money to invest in updating equipment.

Apparently, the hospital was initially founded by a surgeon who then sold it to an investor who profited by making no new investments in it for 10 years. The investor then sold the hospital to a leading healthcare company, which, to turn a profit, made drastic cuts in infrastructure and personnel.

\section{GOING HOME}

Finally, the day of my discharge! No one asked me about the home to which I would return. No one asked me whether there was someone at home to take care of me while I was recuperating.

A secretary entered my room with a sheaf of forms for me to fill out and papers for me to review. Unfortunately, she told me, she had no time to explain any of them to me. I figured out, on my own, that I would have three postoperative visits to the hospital. The days and times of those visits had been arranged without consulting me. Among the numerous papers she gave me, I found a very confusing prescription for multiple medications without any explanation about their dosages and schedules. There was also a prescription for physical therapy at a rehabilitation centre, but again the appointments there had been made without consulting me.

The rehabilitation centre had a business agreement with the hospital but was located in the suburbs, far from my home. How would I manage to get there every day? I also wondered how I would arrange to secure the services of an ambulance company to transport me, since I had been told that I could not put any weight on my hip and leg. I found even the thought of making these arrangements totally exhausting. When I tried to discuss this dilemma with the secretary, I discovered that I should have booked a series of appointments in a physical therapy centre months ago. No one had told me this, so how could I have known? Now, it was too late to find another alternative.

When I explained this to the orthopaedic service secretary, she told me that I was far too demanding a patient and added that, if everyone were like me, well, they would never be able to cope. She was quite blunt about it. "Sir", she announced, "we have no time to handle the details here". Clearly, for the hospital, what happened after I left the premises were irrelevant and irritating details.

\section{Pain at home}

Two days later, I still had more pain than expected. It took me several days to understand that the dose of pain medication could be increased and modulated, and also to discover that the anti-inflammatory medications so 
hard on my stomach were actually unnecessary. I would also have to wait a few more days for my first visit to a physical therapist to learn that placing a thick cushion under my knees at night could reduce my muscle contractions and therefore my pain. This late discovery was even more frustrating as I recalled the sleepless nights in the hospital that could have been made less intolerable. That hospital dealt with patients like me every day. Why didn't they know enough to help? Worse still, if they did know, why didn't they convey this information to patients?

As if this weren't enough, there was the question of the sutures. From home, I phoned the hospital to ask what to do about them. I was told to call a local clinic. So, as per instructions, I went to a local clinic where the nurse examined the wound. The sutures, she told me, had adhered to the skin and would not be easy to remove. "I am not very well paid", she informed me, "I won't take any unnecessary risks, and this is just too complicated." So I had no choice but to go back to the hospital where they removed the sutures.

\section{REFLECTING ON WHAT WENT WRONG}

After I had completely recovered, my new hip worked well. Some might conclude I had no legitimate complains. I think I do. My concern lies with the routine juxtaposition of good technical performance in the operating room with callousness outside of it. How does this juxtaposition arise?

In the weeks of my operation and early recovery, I had encountered more than 50 people and more than 10 different companies-mutual insurance, social security organisation, cardiologist, taxi driver, a community hospital, a laboratory where tests were performed, the ambulance company, the pharmacy, the physiotherapist, the independent home care nurse.... It would be amazing if such a disparate crowd could execute each act and each transition without a glitch. Perhaps the division of labour is just too diverse to allow people to attend to the many difficulties the patient will encounter. Even if everyone performs his or her duty perfectly, problems will inevitably arise. But do these problems have to produce the kinds of responses I encountered?

How is it that healthcare in France and so many other countries is certified by so many agencies and yet what I experienced has so often become the norm? Each specialised auditing agency attests to the quality of various institutions and entities and the various phases of the patient experience. But have they scrutinised the full trajectory of what we as patients experience? Have they explored the details that work and fail to work for vulnerable patients?

My experienced included not just a basic lack of civility, but a disregard for patient care and safety. On the other hand, I was also impressed by the contradiction between the kindness of some caregivers and the pervasive inhumanity of the system in which they work. Although many employees displayed kindness during my stay, their reactions were often very defensive, sometimes hostile. When a patient asked for something that did not exactly conform to their job description, they sought to ignore the requests. Since I had nothing to do but observe, what I noticed was staff seemed to be so overworked and overwhelmed by their duties (remember the hospital had made significant budget cuts to maintain its profit) that they had no time or energy to deal with anything other than their basic duties. Despite good intentions, they couldn't address the plethora of problems a vulnerable patient encounters.

Also, and perhaps more significant, each discrete act and discrete employee is disconnected from the other. Problems occur in the interstices of these disjointed people, in the gaps between the end of one task and the beginning of another, in the hand off between one employee, or one discipline or institution and another. Add to this complexity the problems of inadequate supplies, malfunctioning equipment, overwork and low emotional energy, and the defensiveness, concerns over turf and job descriptions become quite understandable results. For example, when a lovely lady came into my room with my meal tray, I asked her to open my window because I was hot. How did she respond? She told me she was too busy and advised me to buzz for the nurse. If on top of all this, someone lacks a sense of service, then patients are in even more trouble.

My concern here is twofold, one is for patient safety and the other for simple human conduct when dealing with the sick and vulnerable. But both seem to be defeated by the industrialisation of medicine, which has the complexity of an automobile assembly line without its organisation. Some evil genie seems to have pushed the division of labour and preoccupation with productivity to such extremes that many patients are ill treated.

\section{Epilogue}

After my recovery, I decided to write a report of the various events recounted above as well as suggestions for remedying them. These ranged from obvious, concrete improvements, such as purchasing another ice machine and promptly repairing hospital equipment (the light cord, hospital beds), to more substantive changes, such as ensuring that patients know how to take their pain medications and have follow-up appointments at reasonably accessible locations. Although too late for me, I hoped my experiences and suggestions would help other patients. Since the anaesthetist I met initially seemed like a nice and friendly guy, I thought it made 
sense to share the report with him. At first, he was very happy to get my letter and thanked me a lot, promising that he would transmit my report to the director of the hospital as well to the general manager in charge of marketing and communication who, he said, happened to be one of his good friends.

When I saw him again, 2 months later, he admitted that it wasn't possible for him to pass on my report. The hospital was going through yet another reorganisation. The general manager of marketing and communications had just left and he didn't personally know the new one. The situation was confusing and insecure. He had to be careful. It was not a good time to convey any bad news without risking being made a scapegoat because of it.

Acknowledgements I thank Suzanne Gordon for her translation, and Professor Ross Koppel for his further assistance with revisions related to translation.

Competing interests None.

Patient consent Obtained.

Provenance and peer review Commissioned; externally peer reviewed.

\section{REFERENCE}

1. Tucker A, Edmondson A. Why hospitals don't learn from failures: organizational and psychological dynamics that inhibit system change. Calif Manag Rev 2003;45:1-18.

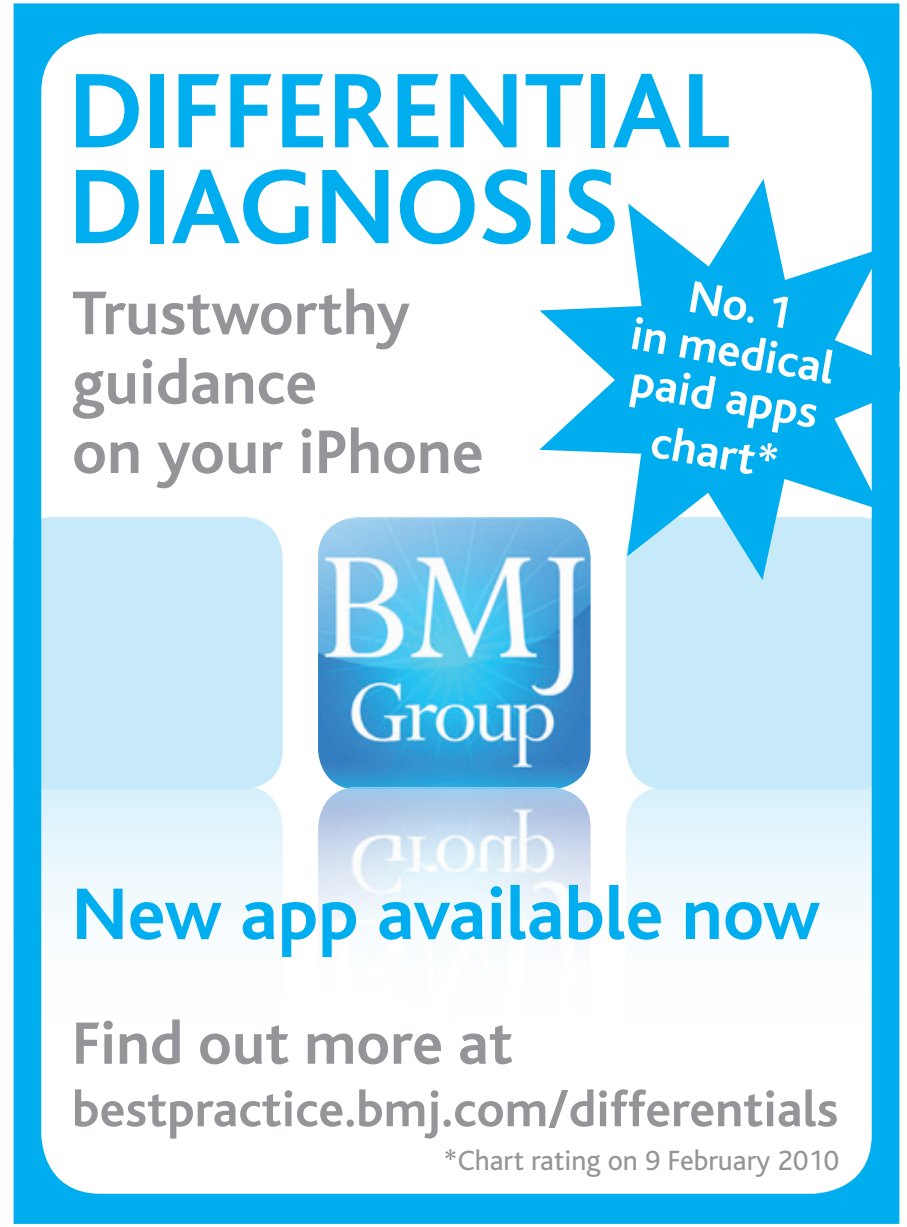

